\title{
PENGARUH PENAMBAHAN HIDROKOLOID DAN KONSENTRASI SUKROSA TERHADAP KARAKTERISTIK FISIK DAN ORGANOLEPTIK SELAI LEMBARAN PEPAYA (Carica Papaya L.)
}

\section{The Effect of Hydrocolloids Addition and Sucrose Concentration on Physical and Organoleptic Characteristics of Pepaya Sheet Jam (Carica Papaya L.)}

\author{
Mulidavi Mutya Rochmah*, M. Khoiron Ferdyansyah, Fafa Nurdyansyah, \\ Rizky Muliani Dwi Ujianti \\ Jurusan Teknologi Pangan, Fakultas Teknik dan Informatika, \\ Universitas PGRI Semarang \\ Jl. Sidodadi Timur No. 24 / Dr. Cipto Semarang \\ *Penulis Korespondensi, Email: mulidavi95@gmail.com
}

\begin{abstract}
ABSTRAK
Buah pepaya adalah buah yang mudah mengalami pembusukan sehingga diperlukan suatu pengolahan untuk meningkatkan daya simpan dari buah pepaya yaitu dibuat menjadi selai lembaran. Penelitian ini bertujuan untuk mengetahui pengaruh penambahan hidrokoloid serta konsentrasi sukrosa terhadap karakteristik fisik dan organoleptik selai lembaran pepaya. Rancangan Acak Lengkap (RAL) Faktorial dengan 2 faktor yaitu penambahan hidrokoloid yang berbeda (konjak, karagenan, campuran konjak dengan karagenan), dan penambahan sukrosa dengan konsentrasi yang berbeda (45\%, 55\% dan $65 \%$ ), ini merupakan metode dalam penelitian ini. Data yang diperoleh akan dianalisis dengan Analysis of Variant (ANOVA) kemudian diuji lanjut dengan DMRT. Hasil penelitian menunjukkan adanya penambahan hidrokoloid dan konsentrasi sukrosa yang berbeda berpengaruh nyata terhadap nilai karakteristik fisik dan uji organoleptik kekenyalan, sedangkan hasil uji organoleptik terhadap nilai kelengketan, rasa, warna, aroma, dan overall tidak berpengaruh secara nyata. Perlakuan terbaik menurut panelis adalah selai lembaran pepaya yang dibuat dari campuran konjak dengan karagenan serta gula $55 \%$.
\end{abstract}

Kata Kunci: Gula, Karagenan, Konjak, Pepaya, Selai.

\begin{abstract}
Papaya fruit is a fruit that is prone to decay, so we need a processing to increase the shelf life of the papaya fruit that is made into jam sheets. This study aims to determine the effect of hydrocolloid addition and sucrose concentration on physical and organoleptic characteristics of papaya jam. Factorial Complete Randomized Design (CRD) with 2 factors, namely the addition of different hydrocolloids (konjac, carrageenan, mixture of konjac with carrageenan), and the addition of sucrose with different concentrations (45\%, 55\% and $65 \%)$, this is the method in this study. The data obtained will be analyzed by Analysis of Variant (ANOVA) then tested further by DMRT. The results showed that the addition of hydrocolloids and different sucrose concentrations significantly affected the physical characteristic value and organoleptic elasticity test, while the organoleptic test results on the value of adhesiveness, taste, color, aroma, and overall had no significant effect. The best treatment according to the panelists was papaya sheet jam made from a mixture of konjac with carrageenan and 55\% sugar.
\end{abstract}

Keywords: Carrageenan, Jam, Konjac, Papaya, Sugar. 


\section{PENDAHULUAN}

Buah pepaya termasuk tanaman dari family Caricaceae dan Genus Carica. Pepaya merupakan buah tropis yang saat ini telah dibudidayakan di Indonesia dan tanamannya sendiri bisa tumbuh sepanjang tahun. Buah pepaya merupakan buah yang cepat mengalami pembusukan, sehingga diperlukan suatu pengolahan yang bertujuan untuk menambah nilai ekonomis dan bisa sebagai diversifikasi produk salah satunya dibuat menjadi selai. Selai sangat digemari oleh masyarakat karena dianggap lebih mudah saat penyimpanan dan lebih awet dibandingkan dengan buah yang masih segar.

Selai yang ada dipasaran umumnya merupakan selai oles, saat penyajiannya masih membutuhkan alat bantu seperti sendok atau pisau untuk mengoleskannya ke permukaan roti. Seiring dengan perkembangan zaman masyarakat menginginkan sesuatu yang lebih simpel sekaligus praktis dalam penyiapannya, sehingga dalam penelitian ini selai oles akan dikembangkan menjadi selai lembaran yang nantinya tetap memiliki rasa khas dari buah yang digunakan. Selai lembaran yang bagus sebaiknya dalam proses pembuatannya bisa ditambah dengan bahan-bahan yang dapat dijadikan sebagai penguat tekstur diantaranya adalah dengan penambahan karagenan dan konjak. Selai lembaran adalah produk makanan semi basah yang bentuknya lembaran, bisa terbuat dari berbagai macam buahbuahan segar. Penelitian terdahulu yang dilakukan oleh Pandiangan (2017) yang menggunakan campuran buah pepaya dan buah terung belanda dengan proporsi yang berbeda, menunjukkan hasil penelitian bahwa rasio bubur pepaya dan bubur terung belanda yang terbaik adalah (20\% bubur pepaya dan $80 \%$ bubur terung belanda). Hidrokoloid yang digunakan tidak diketahui secara pasti dalam penellitian tersebut, sehingga diperlukan penelitian lebih lanjut mengenai hidrokoloid yang tepat dalam pembuatan selai lembaran pepaya.

Karagenan memiliki tipe gel yang kuat dan kokoh, sedangkan konjak memiliki tipe gel yang lunak (Subaryono, 2006). Selai lembaran dianggap baik jika memiliki tektstur tidak terlalu kaku dan tidak terlalu lembek, ini bertujuan agar saat penyajian ke permukaan roti, selai lembaran bisa menyatu dengan roti namun tidak lengket di roti. Untuk menghasilkan tekstur dengan kualitas yang baik maka perlu dilakukan penelitian menggunakan campuran antara konjak dengan karagenan diharapkan dapat diperoleh selai lembaran yang lebih elastis, tidak lembek serta tidak kaku. Selain penambahan hidrokoloid, penambahan gula juga harus diperhatikan dalam pembuatan selai. Gula dapat berfungsi sebagai rasa manis, bisa sebagai pengawet alami dikarenakan gula mampu mengikat air sehingga ketersediaan air untuk pertumbuhan mikroorganisme berkurang (Mutia et al., 2016). Tujuan serta manfaat dari adanya penelitian ini adalah untuk mengetahui pengaruh dari penambahan hidrokoloid dan konsentrasi gula yang berbeda terhadap karakteristik fisik dan organoleptik dari selai lembaran pepaya yang dihasilkan, sehingga selai lembaran yang dihasilkan nantinya bisa dimanfaatkan dalam kehidupan sehari-hari seperti halnya untuk sarapan.

\section{BAHAN DAN METODE}

\section{Bahan}

Penelitian ini menggunakan berbagai macam bahan baku diantaranya buah pepaya jenis Bangkok, konjak, karagenan, gula "Gulaku", asam sitrat, air dan margarin, sedangkan bahan untuk analisis adalah aquades.

\section{Alat}

Pembuatan selai lembaran pepaya alat yang digunakan cukup sederhana diantaranya ada pisau, baskom, telenan, timbangan, blender, gelas ukur, sendok, labu takar $100 \mathrm{ml}$, wajan, kompor gas, spatula, loyang, cabinet dryer, termometer dan label. Bahan yang digunakan untuk analisis diantaranya label, plastik, seperangkat alat gelas dan ekstraksi, dan borang penilaian. 


\section{Desain Penelitian}

Rancangan Acak Lengkap (RAL) Faktorial merupakan metode yang digunakan dalam penelitian ini, metode tersebut melibatkan 2 faktor perlakuan diantaranya penambahan hidrokoloid (konjak, karagenan dan campuran antara konjak dengan karagenan) dengan konsentrasi $3 \%$ dan penambahan sukrosa konsentrasi (45\%,55\% dan 65\%). Setiap unit perlakuan akan dilakukan pengulangan sebanyak 3 kali untuk setiap perlakuan, sehingga nantinya akan ada 27 satuan percobaan. Data analisis menggunakan Analysis of Variant (ANOVA) dan uji beda nyata menggunakan Duncan Multiple Range Test (DMRT) pada taraf signifikansi $5 \%(\alpha=0.05)$. Data yang diperoleh kemudian dianalisis dengan program SPSS for Windows versi 21. Berikut merupakan tabel Rancangan Acak Lengkap (RAL) dalam penelitian ini.

Tabel 1. Perlakuan dengan Rancangan Acak Lengkap (RAL)

\begin{tabular}{lllll}
\hline \multirow{2}{*}{ Hidrokoloid } & \multicolumn{4}{c}{ Konsentrasi Gula } \\
\cline { 2 - 5 }$A_{1}$ & $B_{1}$ & $B_{2}$ & $B_{3}$ \\
$A_{2}$ & $A_{1} B_{1}$ & $A_{2} B_{1}$ & $A_{3} B_{1}$ \\
$A_{3}$ & $A_{1} B_{2}$ & $A_{2} B_{2}$ & $A_{3} B_{2}$ \\
\hline
\end{tabular}

Keterangan:

- $\mathrm{A} 1 \mathrm{~B} 1$ = Konjak;Gula 45\%

- $\quad$ A1B2 = Konjak;Gula 55\%

- $\quad$ A1B3 = Konjak;Gula 65\%

- $\mathrm{A} 2 \mathrm{~B} 1$ = Karagenan;Gula 45\%

- $\mathrm{A} 2 \mathrm{~B} 2$ = Karagenan;Gula 55\%

- A2B3 = Karagenan;Gula 65\%

- $\mathrm{A3B1}=$ Konjak:Karagenan;Gula 45\%

- A3B2 = Konjak:Karagenan;Gula 55\%

- A3B3 = Konjak:Karagenan;Gula 65\%

\section{Tahapan Penelitian}

Proses pembuatan selai lembaran pepaya dilakukan dalam dua tahapan. Pertama adalah pembuatan bubur buah pepaya, buah pepaya yang digunakan adalah buah yang telah matang dengan warna daging buah orange kemerahan. Buah pepaya dicuci terlebih dahulu, selanjutnya dipotong $3 / 4$ bagian lalu dikupas, kemudian dilakukan penghancuran dengan blender. Perbandingan daging pepaya dan air adalah 1:1. Buah pepaya yang telah menjadi bubur buah kemudian dilakukan proses pengolahan ke tahap kedua yaitu dibuat menjadi selai lembaran pepaya. Bubur buah pepaya dimasak dengan suhu $\pm 70^{\circ} \mathrm{C}$ lalu ditambah dengan asam sitrat dan margarin, diaduk kurang lebih selama 2 menit. Hidrokoloid dan gula dicampur sesuai dengan perlakuan lalu diaduk selama 5 menit. Selai yang sudah dimasak lalu dicetak dalam loyang, selanjutnya dikeringkan dalam cabinet dryer suhu \pm $50^{\circ} \mathrm{C}$ selama 20 jam. Proses pembuatan selai lembaran papaya disajikan pada Gambar 1.

\section{Metode Penelitian}

Metode penelitian yang dilakukan adalah pengamatan secara fisik dan organoleptik. Analisis tersebut adalah analisis tekstur (Choy et al., 2010), warna (Hutching, 1999), sineresis (Verawaty, 2008), dan kuat tarik (Setiani et al., 2013). Pengujian organoleptik menggunakan uji kesukaan skala hedonik dengan 30 panelis tidak terlatih. 


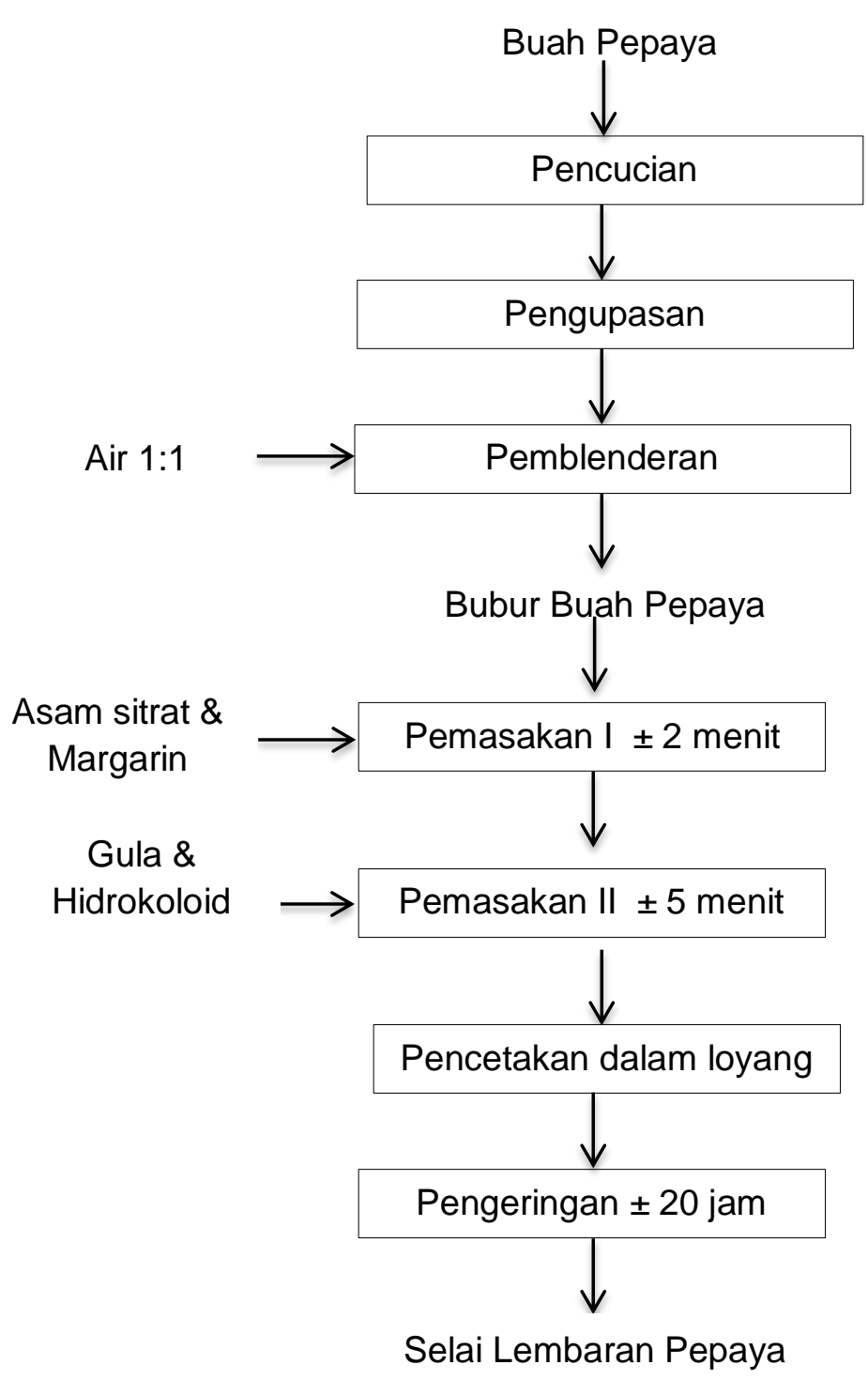

Gambar 1. Proses Pembuatan Selai Lembaran Pepaya

\section{Prosedur Analisis}

Pengujian tekstur dan kuat tarik selai lembaran buah pepaya dilakukan dengan alat texture analyzer dengan tujuan untuk mengukur hardness, springiness, cohesiveness, dan adhesion. Alat texture analyzer akan bekerja dengan cara menekan setiap sampel selai lembaran yang akan diujikan dengan kecepatan $5 \mathrm{~mm} /$ menit, Kemudian data yang diperoleh ditransfer ke dalam komputer lalu dicetak. Pengujian dilakukan sebanyak 3 kali ulangan.

Digital colorimeter merupakan alat yang digunakan untuk analisis warna, dari analisis tersebut akan diperoleh hasil $L^{*}, a^{*}$, dan $b^{*}$. Untuk nilai $L^{*}$ sendiri berarti kecerahan sampel, Nilai $a^{*}$ berarti sampel memiliki derajat kemerah-merahan atau kehijauan. Nilai $b^{*}$ menunjukkan derajat kekuningan atau kebiruan.

Cara pengujian dari analisis sineresis adalah pertama sampel selai lembaran ditimbang sebanyak 15 gram kemudian dimasukkan di dalam plastik yang telah diketahui beratnya lalu selai yang telah dimasukkan ke dalam plastik disimpan pada suhu ruang. Hari berikutnya selai ditimbang kembali apakah telah terjadi proses pengeluaran air (sineresis) atau belum, jika beratnya masih sama dengan hari pertama maka selai tersebut disimpan kembali pada suhu ruang. Hari kedua setelah penyimpanan selai telah mengalami sineresis yang ditandai dengan keluarnya air dari dalam selai lembaran tersebut. Cara menghitung 
berapa banyak selai mengalami sineresis yaitu dengan mengambil selai dari dalam plastik lalu pindahkan selai tersebut kedalam plastik baru yang telah diketahui beratnya kemudian ditimbang. Plastik yang lama juga ditimbang kemudian berat dari plastik akhir ini dikurangi dengan berat plastik awal. Hasil dari pengurangan tersebut merupakan nilai dari sineresis yang didapatkan dari selai lembaran yang telah disimpan selama 2 hari.

Analisis organoleptik menggunakan uji hedonik dengan 30 panelis tidak terlatih. Para panelis dalam menguji kesukaan ini mereka diminta untuk mengungkapkan respon mereka secara individual mengenai suka atau tidak sukanya panelis terhadap sampel selai lembaran pepaya yang disajikan. Umumnya uji kesukaan dilakukan dengan menyajikan parameter nilai di dalam borang penilaian diantaranya kekenyalan, kelengketan, rasa, aroma, warna, dan overall. Tingkat kesukaan panelis dalam pengujiannya menggunakan skala 1-5 yaitu untuk skala rendah menyatakan sangat tidak suka dan skala tertinggi yang menyatakan sangat suka.

\section{HASIL DAN PEMBAHASAN}

\section{Karakteristik Fisik Tekstur Selai Lembaran Pepaya}

Tekstur merupakan salah satu parameter dalam menentukan mutu selai lembaran karena selama proses pengolahan selai akan berhubungan dengan adanya sifat mekanis dari bahan-bahan yang digunakan, sehingga tekstur menjadi kualitas utama dari selai lembaran yang diperoleh. Hasil dari analisis tekstur dapat dilihat pada Tabel 2.

Tabel 2. Hasil Profil Tekstur Selai Lembaran Pepaya

\begin{tabular}{lllll}
\hline Perlakuan & \multicolumn{4}{c}{ Profil Tekstur } \\
\cline { 2 - 5 } & Hardneess & Cohessiveneess & Springiness & Adhesion \\
\hline Konjak;Gula 45\% & $209.67 \pm 52.17^{\mathrm{a}}$ & $0.59 \pm 0.07^{\mathrm{e}}$ & $2.77 \pm 0.25^{\mathrm{bc}}$ & $1.36 \pm 0.33^{\mathrm{b}}$ \\
Konjak;Gula 55\% & $237.50 \pm 10.64^{\mathrm{a}}$ & $0.46 \pm 0.11^{\mathrm{c}}$ & $2.47 \pm 0.57^{\mathrm{b}}$ & $1.33 \pm 1.06^{\mathrm{b}}$ \\
Konjak;Gula 65\% & $632.00 \pm 59.82^{\mathrm{d}}$ & $0.31 \pm 0.07^{\mathrm{ab}}$ & $2.47 \pm 0.57^{\mathrm{b}}$ & $0.97 \pm 0.06^{\mathrm{b}}$ \\
Karagenan ;Gula 45\% & $223.50 \pm 20.78^{\mathrm{a}}$ & $0.24 \pm 0.04^{\mathrm{a}}$ & $3.40 \pm 0.45^{\mathrm{a}}$ & $0.06 \pm 0.04^{\mathrm{a}}$ \\
Karagenan ;Gula 55\% & $383.83 \pm 61.25^{\mathrm{bc}}$ & $0.23 \pm 0.10^{\mathrm{a}}$ & $2.70 \pm 0.87^{\mathrm{bc}}$ & $0.03 \pm 0.02^{\mathrm{a}}$ \\
Karagenan ;Gula 65\% & $646.00 \pm 108.50^{\mathrm{d}}$ & $0.20 \pm 0.05^{\mathrm{a}}$ & $2.33 \pm 0.65^{\mathrm{b}}$ & $0.02 \pm 0.32^{\mathrm{a}}$ \\
Konjak : Karagenan ;Gula 45\% & $357.83 \pm 18.18^{\mathrm{b}}$ & $0.42 \pm 0.02^{\mathrm{bc}}$ & $1.43 \pm 0.11^{\mathrm{a}}$ & $0.38 \pm 0.13^{\mathrm{a}}$ \\
Konjak : Karagenan ;Gula 55\% & $472.50 \pm 43.98^{\mathrm{b}}$ & $0.25 \pm 0.09^{\mathrm{a}}$ & $0.90 \pm 0.20^{\mathrm{a}}$ & $0.11 \pm 0.00^{\mathrm{a}}$ \\
Konjak : Karagenan ;Gula 65\% & $389.87 \pm 67.81^{\mathrm{c}}$ & $0.18 \pm 0.05^{\mathrm{a}}$ & $0.83 \pm 0.15^{\mathrm{a}}$ & $0.07 \pm 0.03^{\mathrm{a}}$ \\
\hline
\end{tabular}

Keterangan :

- Nilai yang dihasilkan merupakan rerata dari 3 kali ulangan

- Angka setelah tanda \pm menunjukkan nilai standard deviasi

- Notasi huruf yang sama setelah hasil rerata ini menyatakan bahwa hasil yang diperoleh tidak berbeda nyata pada uji lanjut DMRT $(\alpha=0.05)$.

\section{Tekstur Hardness}

Hardness atau kekerasan adalah perubahan bentuk pada sampel jika diberikan tekanan atau gaya. Berdasarkan Tabel 2 menunjukkan bahwa dengan adanya penambahan hidrokoloid serta adanya penambahan gula dengan konsentrasi yang berbeda hasilnya antara perlakuan satu dengan perlakuan yang lainnya sangat berbeda nyata. Nilai hardness tertinggi ada pada selai lembaran yang dibuat dengan tambahan hidrokoloid karagenan dan gula $65 \%$. Karagenan memiliki nilai hardness tertinggi karena karagenan memiliki sifat gel yang kuat dan kokoh. Menurut Marzelly et al. (2017) bahwa ikatan-ikatan silang dalam gel karagenan akan membentuk bangunan tiga dimensi yang bersambungan, kemudian jala tersebut akan menangkap air yang ada dalam gel lalu akan membentuk struktur yang tegar serta kaku sehingga tahan terhadap tekanan atau gaya apapun, hal inilah yang menjadikan selai lembaran dari karagenan nilainya tinggi. Adanya penambahan gula dengan konsentrasi lebih tinggi maka nilai hardness yang dihasilkan juga semakin tinggi, ini 
dipengaruhi karena selama proses pemasakan gula akan mengikat air yang ada dalam selai sehingga menghasilkan gel yang lebih keras (Marsigit et al., 2018).

\section{Tekstur Cohessiveness}

Cohesiveness adalah suatu indikasi yang menunjukkan hubungan antara kekuatan atau kekompakkan bahan yang saling berinteraksi. Berdasarkan Tabel 2 cohesiveness berkaitan dengan adanya daya serap pengental gel yang terbentuk pada selai. Daya serap gel dalam selai tinggi maka selai lembaran yang dihasilkan juga memiliki nilai cohesiveness yang tinggi, sehingga menghasilkan selai yang semakin kompak dan padat (Dipowaseso et al., 2018). Adanya proses pengeringan selai, maka akan membuat jaringan pada matriks bahan menjadi padat sehingga akan menaikkan kekompakkan dari selai yang dihasilkan.

\section{Tekstur Springiness}

Springiness atau kelenturan adalah salah satu parameter yang menunjukkan laju perubahan dari sampel selai sampai terjadi perubahan bentuk setelah produk mengalami tekanan. Berdasarkan Tabel 2 menunjukkan adanya penambahan konjak dan karagenan memberikan nilai yang berbeda nyata, sedangkan adanya campuran konjak dengan karagenan memberikan pengaruh yang tidak berbeda nyata. Penurunan nilai springiness dapat dipengaruhi oleh adanya penambahan gula, jika konsentrasi gula yang ditambahkan banyak maka selai lembaran yang dihasilkan akan keras tidak lentur. Menurut Rahmanto et al. (2014) mengungkapkan bahwa adanya penambahan hidrokoloid yang berbeda juga dapat mempengaruhi dari karakteristik selai lembaran yang dihasilkan, penelitian ini yang karakteristiknya baik adalah selai lembaran yang menggunakan tambahan hidrokoloid berupa karagenan.

\section{Tekstur Adhesion}

Adhesion atau kelengketan adalah suatu kecenderungan dari bahan untuk menempel pada bahan lain. Berdasarkan Tabel 2 bahwa adanya penggunaan jenis hidrokoloid karagenan dan campuran antara konjak dengan karagenan hasilnya tidak berbeda nyata, sedangkan selai lembaran yang dibuat dengan tambahan konjak hasilnya berbeda nyata. Nilai adhesion yang tinggi menunjukkan bahwa selai lembaran yang dihasilkan terlalu lengket. Adanya penambahan bahan pembentuk gel dengan konsentrasi rendah maka ikatan antar molekul terhadap air semakin lemah, sehingga selai yang dihasilkan semakin lebih basah dan menyebabkan nilai kelengketan meningkat (Yati et al. 2013). Penambahan gula dengan konsentrasi yang tinggi maka nilai adhesion akan semakin rendah, ini dipengaruhi karena adanya proses pemanasan dimana molekul-molekul $\mathrm{H}_{2} \mathrm{O}$ akan terputus dan menyebabkan molekul-molekul tersebut bergerak dengan cepat dari permukaan dan menjadi gas. Menurut Sinurat (2014) bahwa adanya perpindahan air sebagian dari matriks bahan akan menyebabkan kerapatan dan kelengketan menjadi berkurang.

\section{Karakteristik Warna Selai Lembaran Pepaya}

Warna merupakan atribut penampilan pada suatu produk sehingga konsumen dapat menerima produk tersebut secara keseluruhan. Sistem notasi warna ada 3 parameter yaitu $L^{*}, a^{*}$ dan $b^{*}$. $L^{*}$ adalah tingkat kecerahan, $a^{*}$ yaitu tingkat kemerahan dan $b^{*}$ merupakan tingkat kekuningan hasil analisis warna dapat dilihat pada Tabel 3.

Karakteristik warna untuk hasil dari pengujian $L^{*}, a^{*}$ dan $b^{*}$ menghasilkan nilai positif, nilai tersebut menunjukkan bahwa antara perlakuan satu dengan lainnya hasilnya berbeda sangat nyata. Penambahan konsentrasi gula yang semakin tinggi maka nilai $L^{*}$ dan nilai $b^{*}$ akan menurun, sedangkan nilai $a^{*}$ mengalami peningkatan. Penurunan nilai $L^{*}$ dapat dipengaruhi oleh jumlah air bebas yang menurun menyebabkan jarak antar partikel semakin rapat dan cahaya yang terpantulkan akan lebih sedikit sehingga menyebabkan warna dari selai yang dihasilkan menjadi gelap (Sunyoto et al., 2017). Nilai $a^{*}$ memiliki rerata 37.50 sampai 49.00 . Buah pepaya memiliki pigmen lycopene, jika nilai $a^{*}$ yang dihasilkan semakin rendah tingkat kemerahannya ini menunjukkan bahwa adanya proses pengeringan maka kandungan lycopene yang ada dalam selai lembaran pepaya terdegradasi akibat adanya 
reaksi oksidasi dari perlakuan panas yang diberikan. Warna selai lembaran pepaya ditentukan oleh warna dari buah pepaya yang digunakan, dimana dengan adanya proses pemanasan, gula serta komponen asam akan saling berinteraksi jika dipanaskan sehingga terjadi proses inversi sukrosa dan ini menyebabkan perubahan warna pada selai lembaran pepaya yang dihasilkan (Javanmard, 2010).

Tabel 3. Profil Analisis Warna Selai Lembaran Pepaya

\begin{tabular}{llll}
\hline Perlakuan & \multicolumn{3}{c}{ Unsur Warna } \\
\cline { 2 - 4 } & $\mathrm{L}^{*}($ Kecerahan) & $\mathrm{a}^{*}$ (Kemerahan) & $\mathrm{b}^{*}$ (Kekuningan) \\
\hline Konjak; Gula 45\% & $43.75 \pm 1.50^{\mathrm{c}}$ & $37.50 \pm 2.38^{\mathrm{a}}$ & $53.25 \pm 1.26^{\mathrm{e}}$ \\
Konjak; Gula 55\% & $43.50 \pm 1.29^{\mathrm{e}}$ & $41.25 \pm 0.96^{\mathrm{b}}$ & $52.75 \pm 1.50^{\mathrm{e}}$ \\
Konjak; Gula 65\% & $36.25 \pm 0.96^{\mathrm{e}}$ & $41.50 \pm 1.29^{\mathrm{b}}$ & $47.25 \pm 0.96^{\mathrm{c}}$ \\
Karagenan; Gula 45\% & $39.00 \pm 0.81^{\mathrm{d}}$ & $39.50 \pm 1.00^{\mathrm{b}}$ & $49.75 \pm 0.96^{\mathrm{d}}$ \\
Karagenan; Gula 55\% & $33.75 \pm 1.90^{\mathrm{b}}$ & $44.00 \pm 1.15^{\mathrm{c}}$ & $45.25 \pm 0.96^{\mathrm{b}}$ \\
Karagenan; Gula 65\% & $31.50 \pm 1.73^{\mathrm{a}}$ & $49.00 \pm 1.41^{\mathrm{e}}$ & $38.25 \pm 0.50^{\mathrm{a}}$ \\
Konjak : Karagenan; Gula 45\% & $40.25 \pm 0.96^{\mathrm{d}}$ & $39.50 \pm 0.57^{\mathrm{b}}$ & $48.75 \pm 1.26^{\mathrm{cd}}$ \\
Konjak : Karagenan; Gula 55\% & $39.50 \pm 0.58^{\mathrm{d}}$ & $41.00 \pm 0.81^{\mathrm{b}}$ & $48.00 \pm 0.82^{\mathrm{c}}$ \\
Konjak : Karagenan; Gula 65\% & $34.25 \pm 0.96^{\mathrm{b}}$ & $48.00 \pm 0.81^{\mathrm{e}}$ & $45.50 \pm 1.00^{\mathrm{b}}$ \\
\hline
\end{tabular}

Keterangan :

- Nilai yang dihasilkan merupakan rerata dari 3 kali ulangan

- Angka setelah tanda \pm menunjukkan nilai standard deviasi

- Notasi huruf yang sama setelah hasil rerata ini menyatakan bahwa hasil yang diperoleh tidak berbeda nyata pada uji lanjut DMRT ( $\alpha=0.05)$.

\section{Karakteristik Kuat Tarik Selai Lembaran Pepaya}

Pengujian kuat tarik diperoleh berdasarkan gaya yang dibutuhkan dalam merenggangkan selai lembaran pepaya hingga terputus. Hasil analisis dapat dilihat pada Gambar 2.

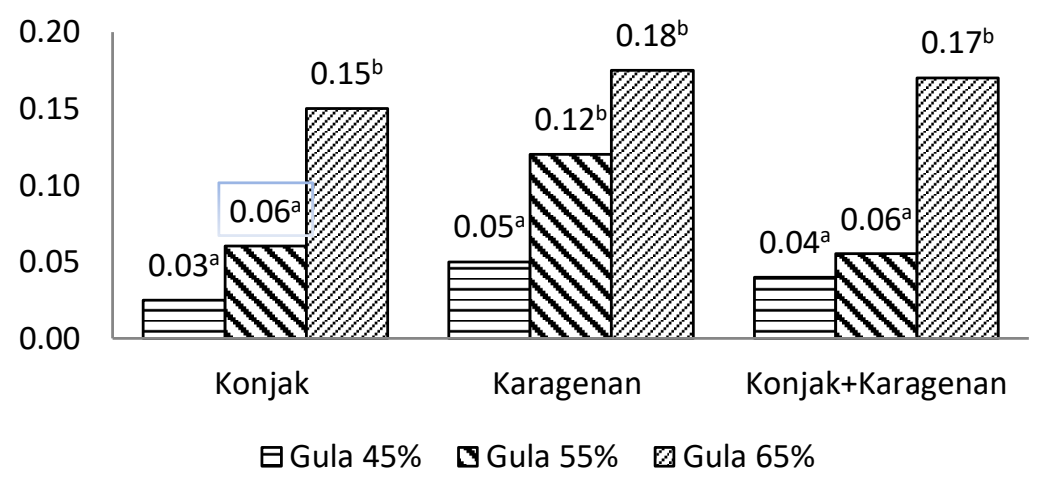

Gambar 2. Pengaruh Konsentrasi Gula dan Perbedaan Jenis Hidrokoloid Terhadap Kuat Tarik Selai Lembaran Pepaya.

Nilai kuat tarik tertinggi ada pada perlakuan yang ditambah dengan karagenan dan gula $65 \%$ yaitu $0.18 \mathrm{Mpa}$. Nilai kuat tarik yang semakin tinggi menunjukkan bahwa selai yang dihasilkan memiliki ketahanan terhadap gaya tarik yang lebih baik sehingga tidak mudah putus. Konsentrasi gula yang semakin tinggi akan semakin menguatkan matriks selai lembaran pepaya yang dihasilkan, ini disebabkan karena adanya proses pembentukan gel, dimana gel yang terbentuk akan menagkap air didalamnya (Amaliya, 2014). 


\section{Karakteristik Sineresis Selai Lembaran Pepaya}

Sineresis adalah peristiwa keluarnya air dari dalam gel di karenakan adanya kontraksi dari dalam gel yang diakibatkan karena terbentuknya ikatan-ikatan baru antar polimer dari struktur gel. Hasil analisis dapat dilihat pada Gambar 3.

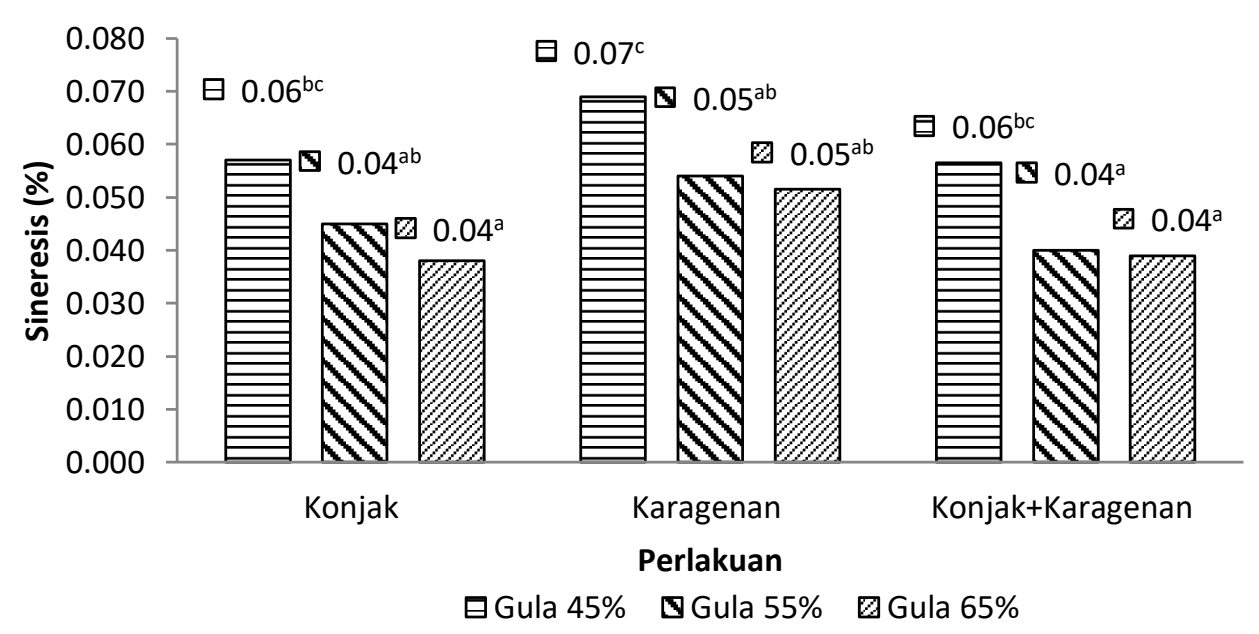

Gambar 3. Pengaruh Konsnetrasi Gula dan Perbedaan Jenis hidrokoloid Terhadap Nilai Sineresis Selai Lembaran Pepaya.

Nilai sineresis dapat dilihat pada Gambar 3. dimana nilai sineresis yang dihasilkan memiliki rerata $0.04-0.07 \%$. Selai yang dianggap baik jika nilainya dibawah kisaran $0-5 \%$, ini menunjukkan bahwa selai lembaran pepaya yang dihasilkan tidak terjadi proses sineresis serta memiliki kualitas yang baik (Croptova, 2013). Adanya penambahan gula dengan konsentrasi yang semakin tinggi akan menurunkan nilai sineresis, hal ini dipengaruhi karena molekul air yang tertahan pada sistem semakin sedikit sehingga gel yang terbentuk akan semakin kokoh dan menghasilkan nilai sineresis yang rendah. Gula bersifat hidrofilik karena gula memiliki gugus hidroksil dalam struktur molekulnya, kemudian gugus hidroksil akan mengikat molekul air melalui ikatan hidrogen, sehingga air yang ada dalam produk akan berkurang, oleh karena itu selai lembaran yang dihasilkan akan semakin kental dan ini akan menurunkan tingkat sineresis pada selai yang dihasilkan (Winarno, 1996).

\section{Karakteristik Organoleptik Selai Lembaran Pepaya}

Uji organoleptik dilakukan dengan tujuan untuk mengetahui seberapa suka atau tidak sukanya panelis terhadap produk yang dihasilkan. Pengujian organoleptik menggunakan metode hedonik atau kesukaan dengan jumlah panelis adalah 30 orang. Parameter yang diujikan dalam uji organoleptik ini adalah kelengketan, kekenyalan, warna, aroma, rasa dan overall. Hasil analisis dari uji organoleptik dapat dilihat pada Tabel 4.

\section{Kekenyalan}

Tingkat kesukaan panelis terhadap tekstur kekenyalan selai lembaran pepaya berbeda secara nyata antara perlakuan satu dengan lainnya. Semakin banyak gula yang ditambahkan maka selai lembaran yang dihasilkan tidak kenyal dan cenderung teksturnya keras. Nilai kekenyalan yang semakin tinggi akan menurunkan tingkat penerimaan konsumen terutama penerimaan kegunaan pada suatu produk. Sifat kegunaan dalam selai lembaran penting dilakukan mengingat selai nantinya akan dikonsumsi bersamaan dengan roti selai lembaran yang dihasilkan sebaiknya memiliki sifat yang cenderung basah tetapi mudah dikunyah (Septiani, 2013). Adanya penambahan hidrokoloid karagenan akan menghasilkan selai yang kokoh dan kuat dibandingkan dengan yang ditambah dengan konjak, sehingga panelis tidak menyukai selai yang teksturnya terlalu keras. 
Tabel 4. Pengaruh Penambahan Gula dan Jenis Hidrokoloid Terhadap Nilai Organoleptik Kesukaan.

\begin{tabular}{lllllll}
\hline \multirow{2}{*}{ Perlakuan } & \multicolumn{5}{c}{ Parameter } \\
\cline { 2 - 6 } & Kekenyalan & Kelengketan & Rasa & Aroma & Warna & Overall \\
\hline A1B1 & $3.67 \pm 1.12^{\mathrm{d}}$ & $3.20 \pm 1.24^{\mathrm{a}}$ & $3.33 \pm 0.96^{\mathrm{a}}$ & $3.13 \pm 0.98^{\mathrm{a}}$ & $3.50 \pm 0.87^{\mathrm{a}}$ & $3.47 \pm 0.82^{\mathrm{a}}$ \\
A1B2 & $3.83 \pm 1.00^{\mathrm{d}}$ & $3.37 \pm 1.13^{\mathrm{a}}$ & $3.53 \pm 1.00^{\mathrm{a}}$ & $3.30 \pm 1.08^{\mathrm{a}}$ & $3.73 \pm 0.83^{\mathrm{a}}$ & $3.40 \pm 1.07^{\mathrm{a}}$ \\
A1B3 & $3.23 \pm 1.16^{\mathrm{bc}}$ & $3.07 \pm 1.11^{\mathrm{a}}$ & $3.53 \pm 0.89^{\mathrm{a}}$ & $3.30 \pm 1.08^{\mathrm{a}}$ & $3.40 \pm 0.72^{\mathrm{a}}$ & $3.47 \pm 0.97^{\mathrm{a}}$ \\
A2B1 & $2.60 \pm 1.27^{\mathrm{ab}}$ & $2.87 \pm 1.00^{\mathrm{a}}$ & $3.27 \pm 1.05^{\mathrm{a}}$ & $3.37 \pm 0.80^{\mathrm{a}}$ & $3.57 \pm 0.97^{\mathrm{a}}$ & $3.33 \pm 1.03^{\mathrm{a}}$ \\
A2B2 & $2.93 \pm 1.00^{\mathrm{ab}}$ & $3.07 \pm 1.08^{\mathrm{a}}$ & $3.03 \pm 0.89^{\mathrm{a}}$ & $3.40 \pm 0.97^{\mathrm{a}}$ & $3.60 \pm 0.77^{\mathrm{a}}$ & $3.27 \pm 0.91^{\mathrm{a}}$ \\
A2B3 & $2.57 \pm 1.13^{\mathrm{a}}$ & $2.73 \pm 1.23^{\mathrm{a}}$ & $3.30 \pm 0.95^{\mathrm{a}}$ & $3.03 \pm 1.16^{\mathrm{a}}$ & $3.50 \pm 0.90^{\mathrm{a}}$ & $3.33 \pm 0.80^{\mathrm{a}}$ \\
A3B1 & $3.20 \pm 1.09^{\mathrm{abc}}$ & $3.00 \pm 1.14^{\mathrm{a}}$ & $3.23 \pm 0.86^{\mathrm{a}}$ & $3.17 \pm 1.08^{\mathrm{a}}$ & $3.50 \pm 0.77^{\mathrm{a}}$ & $3.23 \pm 0.72^{\mathrm{a}}$ \\
A3B2 & $3.20 \pm 1.21^{\mathrm{abc}}$ & $3.10 \pm 1.18^{\mathrm{a}}$ & $3.37 \pm 1.19^{\mathrm{a}}$ & $3.10 \pm 0.99^{\mathrm{a}}$ & $3.77 \pm 0.97^{\mathrm{a}}$ & $3.67 \pm 0.92^{\mathrm{a}}$ \\
A3B3 & $3.00 \pm 0.98^{\mathrm{ab}}$ & $2.93 \pm 1.08^{\mathrm{a}}$ & $3.50 \pm 1.07^{\mathrm{a}}$ & $3.30 \pm 1.20^{\mathrm{a}}$ & $3.50 \pm 0.90^{\mathrm{a}}$ & $3.47 \pm 0.77^{\mathrm{a}}$ \\
\hline
\end{tabular}

Keterangan :

- Nilai yang dihasilkan merupakan rerata dari 3 kali ulangan

- Angka setelah tanda \pm menunjukkan nilai standard deviasi

- Notasi huruf yang sama setelah hasil rerata ini menyatakan bahwa hasil yang diperoleh tidak berbeda nyata pada uji lanjut DMRT ( $\alpha=0.05)$.

\section{Kelengketan}

Kelengketan menunjukkan daya lekat selai lembaran terhadap roti, selai lembaran yang baik sebaiknya tidak lengket pada roti saat disajikan. Berdasarkan hasil analisis menunjukkan bahwa tingkat kesukaan panelis terhadap kelengketan selai lembaran pepaya antara perlakuan satu dengan lainnya hasilnya tidak berbeda nyata. Selai lembaran pepaya yang dihasilkan memiliki kelengketan yang cukup baik karena panelis menilai selai yang dihasilkan tidak lengket ditangan. Adanya proses pemanasan akan menyebabkan kandungan air pada bagian permukaan selai lembaran menjadi berkurang, sehingga akan merapatkan ikatan antar matriks pembentuk gel sehingga membuat tekstur semakin lengket akibat adanya gula yang dipanaskan (Mawarni et al., 2018).

\section{Rasa}

Berdasarkan hasil uji organoleptik rasa panelis menunjukkan hasil bahwa rasa dari selai lembaran pepaya tidak berbeda nyata. Rasa dapat dipengaruhi oleh adanya interaksi dengan bahan lain. Perbedaan rasa dari selai lembaran pepaya tidak bisa dibedakan oleh panelis karena penggunaan buah pepaya pada semua perlakuan beratnya sama. Penggunaan konjak dan karagenan dalam penelitian memberikan pengaruh netral terhadap rasa, karena konjak dan karagenan tidak memiliki rasa. Penggunaan gula dengan konsentrasi yang semakin tinggi juga tidak berpengaruh terhadap rasa dari selai lembaran pepaya karena, gula dalam penelitian ini tidak mengalami proses karamelisasi sehingga tidak terbentuk rasa karamel.

\section{Aroma}

Aroma merupakan faktor yang menjadi daya tarik terhadap produk yang dihasilkan. Berdasarkan hasil uji organoleptik aroma tersebut menunjukkan bahwa adanya penambahan gula serta hidrokoloid yang berbeda memberikan pengaruh antara perlakuan satu dengan lainnya hasilnya tidak berbeda nyata. Aroma dari selai lembaran pepaya dalam penelitian ini cenderung memiliki aroma khas buah pepaya dibandingkan dengan bahanbahan lainnya, karena penggunaan buah pepaya jumlahnya lebih besar daripada penggunaan konjak, karagenan dan gula. Adanya penambahan gula juga tidak menimbulkan karamelisasi sehingga aroma yang dihasilkan masih khas buah pepaya. 


\section{Warna}

Warna merupakan faktor paling penting dalam menentukan seberapa baikkah kualitas dari bahan pangan tersebut. Bahan pangan yang tekstur yang baik serta rasanya enak tetapi warnanya menyimpang maka produk tersebut tidak akan dimakan (Andarwulan et al. 2011). Hasil analisis menunjukkan adanya penambahan hidrokoloid dan konsnetrasi gula yang semakin tinggi tidak berpengaruh secara nyata. Penggunaan konsentrasi gula yang berlebih cenderung menurunkan tingkat kesukaan panelis karena dengan semakin tinggi gula yang dihasilkan warna selai lembaran pepaya menjadi lebih gelap. Warna selai lembaran pepaya yang semakin gelap akan menurunkan tingkat kesukaan panelis, karena mereka menggangap selai yang dihasilkan sudah lama disimpan sehingga warnanya cenderung gelap.

\section{Overall}

Penerimaan secara keseluruhan menunjukkan penilaian panelis secara umum terhadap suatu produk, bukan merupakan faktor penentu untuk menentukan produk pangan yang terpilih. Hasil analisis dari uji organoleptik secara keseluruhan mencakup penilaian terhadap parameter dari mulai aroma, tekstur (kekenyalan dan kelengketan), rasa, dan warna. Penilaian secara keselurahan memberikan pengaruh yang tidak berbeda nyata antara perlakuan satu dengan yang lainnya, penilaian panelis dalam penelitian ini masih dalam tahap agak suka. Tingkat kesukaan tertinggi ada pada selai lembaran pepaya yang dibuat dari campuran antara konjak dengan karagenan serta gula 55\%. Penilaian ini menunjukkan bahwa selai yang dihasilkan tidak terlalu kenyal dan tidak lengket ditangan, memiliki warna khas buah pepaya yaitu orange kemerahan, rasanya tidak terlalu manis, sedangkan dari segi aroma selai lembaran yang dihasilkan memiliki aroma pepaya yang tidak terlalu kuat.

\section{SIMPULAN}

Hasil penelitian menunjukkan adanya penambahan jenis hidrokoloid serta semakin tinggi konsentrasi gula yang ditambahkan berpengaruh nyata terhadap nilai tekstur hardness, cohesiveness, springiness, adhesion, kuat tarik, warna $\mathrm{L}^{*}$, warna $\mathrm{a}^{*}$, warna $\mathrm{b}^{*}$, dan sineresis. Hasil analisis uji organoleptik menunjukkan bahwa adanya penambahan hidrokoloid dan gula berpengaruh nyata terhadap tingkat kesukaan kekenyalan, sedangkan untuk tingkat kesukaan kelengketan, warna, aroma, rasa, dan overall menunjukkan hasil yang tidak berpengaruh secara nyata. Perlakuan terbaik diperoleh pada selai lembaran pepaya yang dibuat dari campuran antara konjak dengan karagenan serta gula konsentrasi $55 \%$ dengan nilai hardness sebesar $472 \mathrm{gr}$, cohesiveness sebesar 0.25 , springiness sebesar $0.09 \mathrm{~mm}$, adhesion sebesar $0.11 \mathrm{~mJ}$, warna $\mathrm{L}^{*}$ sebsear 39.50 , warna $\mathrm{a}^{*}$ sebesar 41.00, warna $b^{*}$ sebesar 48.00 , sineresis $0.04 \%$, dan kuat tarik sebesar 0.06 Mpa. Skor terhadap organoleptik menunjukkan bahwa tingkat penilaian panelis terhadap parameter kelengketan 3.10, kekenyalan 3.20, warna 3.77, rasa 3.37, aroma 3.10 dan overall 3.67. Penilain tersebut masih berada dalam tahap agak suka, panelis menilai bahwa selai lembaran pepaya yang dihasilkan tidak terlalu kenyal dan tidak lengket ditangan, warnanya menarik, aroma pepaya tidak terlalu terasa dan rasanya tidak terlalu manis. Kekurangan dari penelitian ini juga dipengaruhi oleh aroma buah pepaya yang kurang disukai oleh panelis, sehingga diperlukan penambahan bahan lain untuk mengurangi aroma khas dari buah pepaya.

\section{DAFTAR PUSTAKA}

Amaliya, R.R. dan Putri, W.D.R. 2014. Karakteristik edible film dari pati jagung dengan penambahan filtrat kunyit putih sebagai antibakteri. JPA. 2, 43-53.

Andrawulan W. dan Palupi V.S. 2011. Metode dan Teknologi dalam Penelitian Mutu Praktikum Analisis Fisika dan Kimia. Pelatihan Singkat Pengendalian Mutu Industri Pangan. PAU Pangan dan Gizi, Institut Pertanian Bogor. Bogor. 
Choy, A.L., Hughes, J.G. dan Small, D.M. 2010, The Effect of Microbial Transglutaminase, Sodium Steroyl Lactylate and Water on The Quality of Instant Fried Noodles. Journal of Food Chemistry 122:957-964.

Croptova. J. dan Popel S.2013. A way to prevent syneresis in fruit filling prepared with gellan gum. J. Anim. Sci.6:326-332.

Dipowaseso, D.A., Nuwantoro, dan Hintono, A. 2018. Karakteristik Fisik dan Daya Oles Selai Kolang-Kaling yang Dibuat Melalui Substitusi Pektin dengan Modified Cassava Flour (MOCAF) sebagai Bahan Pengental. Jurnal Teknologi Pangan 2(1) ; 1-7.

Hutching, J.B. 1999. Food Color and Appearance. Marylan: Aspen publisher Inc

Javanmard M., Chin N.L., Yusof Y.A. dan Endan J. 2010. Application of sago starch as a gelling agent in jam. CyTA-J. Food. 10(4): 275-286.

Marsigit, W., Tutuarima, T. dan Hutapea, R. 2018. Pengaruh Penambahan Gula dan Karagenan Terhadap Karakteristik Fisik, Kimia dan Organoletik Soft Candy Jeruk Kalamansi (Citrofortunella Microcarpa). Jurnal Agroindustri 8(2) ; 113-123.

Marzelly, A.D., Yuwanti, S.; dan Lindriati, T. 2017. Karakteristik Fisik, Kimia, dan Sensoris Fruit Leather Pisang Ambon (Musa Paradisiaca S.) dengan Penambahan Gula dan Karagenan. Jurnal Agroteknologi 11(02); 173-185

Mawarni, S.A. dan Yuwono, S.S. 2018. Pengaruh Lama Pemasakan dan Konsentrasi Karagenan Terhadap Sifat Fisik, Kimia dan Organoleptik Selai Lembaran Mix Fruit (Belimbing dan Apel. Jurnal Pangan dan Agroindustri 6(2); 33-41.

Mutia, A.K., dan Yunus, R. 2016. Pengaruh Penambahan Sukrosa pada Pembuatan Selai Langsat. Jtech 4(2); $80-84$.

Pandiangan, A., Faizah, H. dan Rahmayuni. 2017. Pembuatan Selai Campuran Buah Pepaya dan Buah Terung Belanda. Jom Fakultas Pertanian. 4 (2); 1-15.

Rahmanto, S.A., Parnanto, N.H.R. dan Nursiwi, A. 2014. Penambahan gum arab menggunakan metode accelerated shelf life test (ASLT) model arrhenius. Jurnal Teknosains Pangan. 3 (3); 35-45.

Septiani, I.N., Basito dan E.W. 2013. Pengaruh Konsentrasi Agar-Agar dan Karagenan Terhadap Karakteristik Fisik, Kimia, dan Sensori Selai Lembaran Jambu Biji Merah (Psidium guajava L.)". Jurnal Teknologi Hasil Pertanian, 6(1); 27-35

Setiani, W., Sudiarti, T. dan Rahmidar, L. 2013. Preparasi dan Karakterisasi Edible Flim dari Poliblend Pati Sukun-Kitosan. Valensi 3(2) ; 100-109.

Sinurat, E. dan Murniyati. 2014. Pengaruh waktu dan suhu pengeringan terhadap kualitas permen jeli. Jurnal Pascapanen dan Bioteknologi Kelautan dan Perikanan. 9, 133142.

Subaryono, U. dan Bandol, B.S. 2006. Pengggunaan Campuran Karagenan dan Konjak dalam Pembuatan Permen Jelly. Jurnal Pascapanen dan Bioteknologi Kelautan dan Perikanan 1(1).

Sunyoto, R.K., Suseno, T.I.P. dan Utoma, A.R. 2017. Pengaruh Konsentrasi Agar Batang Terhadap Karakteristik Fisikokimia dan Organoleptik Selai Murbei Hitam (Morus nigra L.) Lembaran. Jurnal Teknologi Pangan dan Gizi. 16(1); 1-7.

Verawaty. 2008. Pemetaan Tekstur dan Karakteristik Gel Hasil Kombinasi Karagenan dan Konjak. Skripsi. Bogor: Fakultas Teknologi Pertanian. Institut Pertanian Bogor. Bogor.

Winarno, F.G. 1996. Kimia Pangan dan Gizi. Gramedia Pustaka Utama. Jakarta.

Yati, K., Hariyanti., dan Desnita. 2013. Pengaruh Peningkatan Konsentrasi Kombinasi Karagenan dan Konjak Sebagai Gelling Agent Terhadap Stabilitas Fisik Kembang Gula Jelly Sari Umbi Wortel. Farmasains 2(1); 20-25. 